\title{
Mini Wireless ECG for Monitoring Athletes' ECG Signal Based on Smartphone
}

\author{
Radian Sigit ${ }^{1)}$, Sugondo Hadiyoso $^{2)}$, Achmad Rizal $^{3)}$, Koredianto Usman $^{4)}$ \\ 1,3,4 Faculty of Engineering, Telkom University \\ ${ }^{2}$ Applied Science School, Telkom University
}

\begin{abstract}
Electrocardiogram (ECG) is biopotenstial signal produced from electrical activity of the heart. ECG signal provides information related to health condition. In this research, we designed small, portable, wireless ECG for athletes monitoring. The system consists of hardware for ECG signal acquisition and bluetooth module for data transmission. To facilitate the mobility of athletes, we use modified chest leads using 3 electrodes. Application for displaying ECG signal installed on smart-phone that receives signals via bluetooth. From the test results, ECG signal can be received well until a maximum distance of 20 meters with 10 sample data frame / frames and baudrate of $38,400 \mathrm{bps}$
\end{abstract}

Keywords: - ECG, bluetooth, smartphone, wireless monitoring

\section{INTRODUCTION}

Electrocardiogram (ECG) is a physiological signal generated by the electrical activity of heart. By looking at the form, rhythm and orientation of the ECG signal one can check health condition of heart [1]. The most basic information that can be retrieved from the ECG signal is the number of heart beats per minute. This parameter is usually used to determine a person's fitness level. Those who are closely concerned with the measurement of fitness level are athletes and their coaches. ECG is generally monitored by coaches to observe the training of athletes.

In previous research has a portable ECG device using wireless LAN $802.11 \mathrm{~b}$ protocols has been successfully designed and made [2]. One problem that has not resolved yet is the relatively big dimension of these ECG device so users can not bring ECG devices freely.

Looking at the needs and problems that still exist in previous research, this project built a mini ECG device with wireless transmission based on smart-phones. Mini wireless ECG device consists of a mini-sized hardware that can be used without interfering with user activities. ECG signal acquired will be sent via bluetooth protocol and displayed on the smart-phone screen. With this system, heart conditions of practicing athletes can always be monitored by a coach.

\subsection{Electrocardiograph}

\section{THEORY}

ECG signal is a signal generated by the heart as the representation of the electrical activity of the heart. Looking at the ECG signal will reveal to a person's level of cardiovascular health. ECG signals are assessed from form, orientation and rhythm. ECG signal shape appears as in Figure 1.

There are two modes in the measurement of ECG signals: diagnostic mode and monitoring mode. In diagnostic mode, there is a wider frequency response range of $0.05-100 \mathrm{~Hz}$. The high-frequency limit of $100 \mathrm{~Hz}$ ensures that tracings allow assessment of QRS morphology and tachyarrhythmias (rapid heart beat)[3]. In the monitoring mode, the bandwidth used from 0.5 to $40 \mathrm{~Hz}$. Narrow band is intended to reduce noise due to body movement and breathing [3]. In monitor mode, the required information is not very detailed and generally focuses on heart's rhythm. 


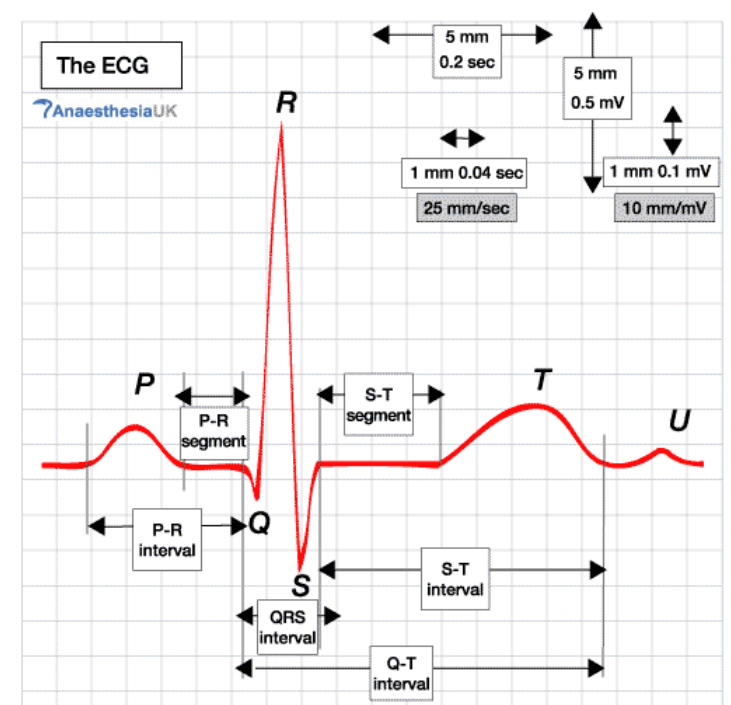

Figure 1. Normal ECG Signal[3]

Each wave of the ECG signal is expressed as follows [4]:

1. P wave occurs due to atrium depolarization.

2. QRS complex occurs due to ventricular depolarization process.

3. T wave occurs due to ventricular repolarization.

4. PR interval indicates the time of onset of atrium contraction to the beginning of ventricular contraction.

5. RT intervals showed muscle contraction (systole ventricle), and

6. TR interval showed muscle relaxation (diastole ventricle).

A pair of electrodes, or a combination of several electrodes, to take the ECG signal is called a lead. The technique which is often used for lead to capture ECG signals on ECG monitoring is Einthoven triangle. The placement of the electrodes to take ECG signal from body using Einthoven's triangle is shown in Figure 2.

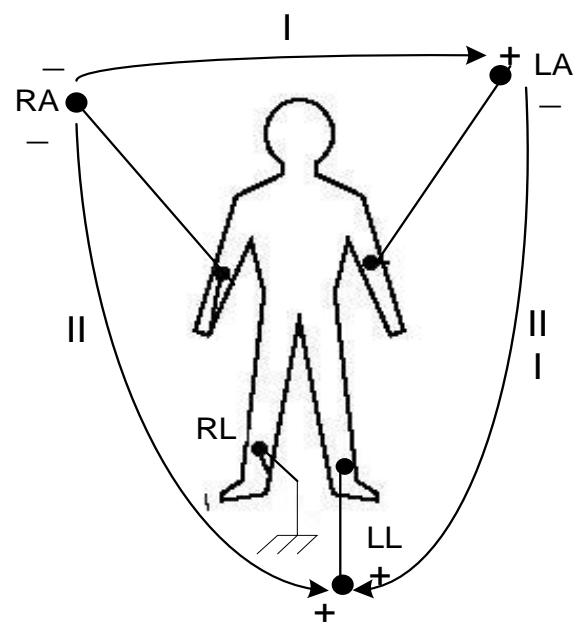

Figure 2. Einthoven Triangle[4]

On Einthoven's triangle there are three point lead, i.e leas I, lead II and lead III. Lead I, is the potential difference between the left arm and right arm. Lead II, is the potential difference between the left leg and right arm. Lead III, is the potential difference between the left-hand leg and left arm. Meanwhile right leg serves as a ground to reduce noise.

In athletes, ECG device taps ECG signal from users who are moving continuously, thus the use of Einthoven's triangle becomes impractical. This is normally due the use of long cables to reach the arms and legs. To solve these problem, then we used modified chest lead technique as in Figure 3. 

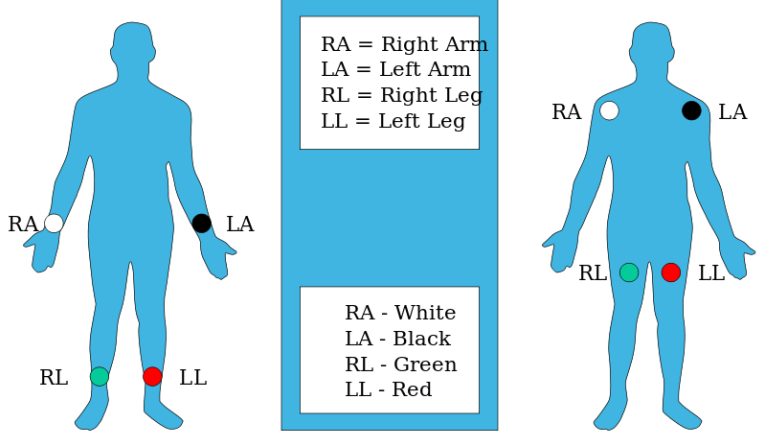

Figure 3. Einthoven Triangle dan modified chest lead [5]

Modified chest lead is a method that is applied to the Einthoven triangle. In this method, position of the leads is not positioned in the limbs in general but rather placed on the patient's chest area. This method has several advantages, such as:

1. Maximizing the $\mathbf{P}$ wave during dysrhytmia.

2. Increasing electrodes sensitivity on ischaemia monitoring system.

3. Minimizing noise artefacts caused the body due to muscle movement that occurs in the limbs.

\section{SYSTEM DESIGN}

System designed of this project is as shown in Fig. 6. The ECG device is installed on the user side with combination of electrode based on modified chest lead. Then, ECG signal is transmitted using Bluetooth module. ECG signal is received by the coach's smart phone so that athlete's heart condition can be observed from long distance while exercising.

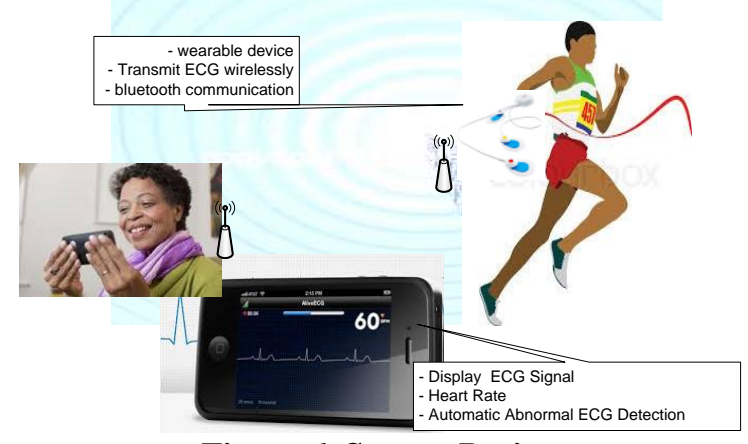

Figure 6. System Design

Mini ECG device consists of two parts: hardware for ECG signal acquisition and transmission, while the second part is application software on smart phone to display the ECG signal. In the following sections, the system design is described.

\subsection{ECG's Hardware}

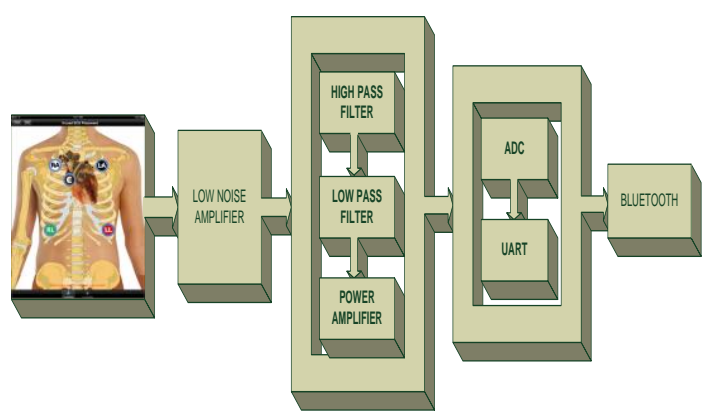

Figure 7. Block Diagram of the ECG Devices 
Instrumentation amplifier is first amplifier circuit to amplify small signals (ECG's amplitude only $3 \mathrm{mV})$. This instrument amplifier is using IC AD620 with a gain resistor $(\mathrm{Rg}=10 \mathrm{k} \Omega)$. According to the equation, the value of gain is:

$$
G=1+\frac{49.4 k}{10 k}=5.94
$$

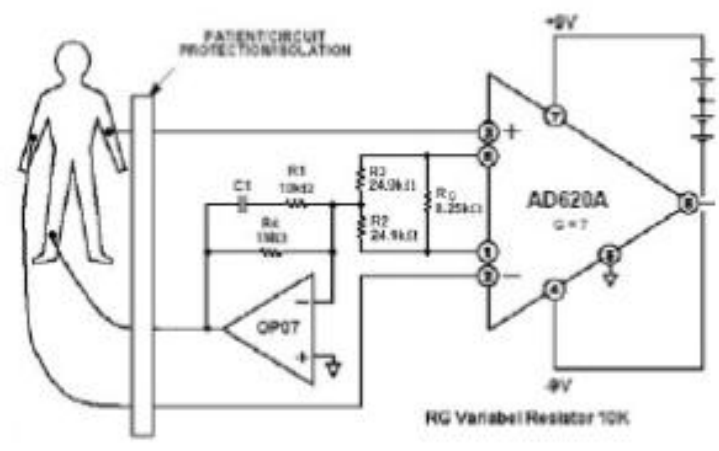

Figure 8. Instrumentation Amplifier Design[6]

The range frequency used for ECG monitoring system is $0.05 \mathrm{~Hz}-40 \mathrm{~Hz}$. Cut-off frequency of LPF filter at $40 \mathrm{~Hz}$ and HPF at $0.05 \mathrm{~Hz}$. Once the signal is filtered, signal is amplified 100 times by a non-inverting operational amplifier so that signal has large enough amplitude to be read by digital subsystem. Digital subsystem is a minimum system of ATmega328P microcontroller as analog to digital signal converter and transfer the data to Bluetooth module [7].

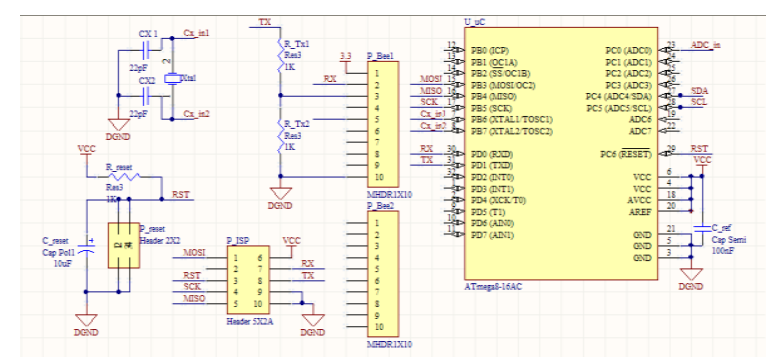

Figure 9. Minimum System of ATMega328P

\subsection{ECG's Application Software}

When the device receives a command execution from the smart phone, the microcontroller will read data as much as buffer capacity. Once the buffer is full, the device will transmit data to smart phone. Flowchart of program can be seen in Fig. 10.

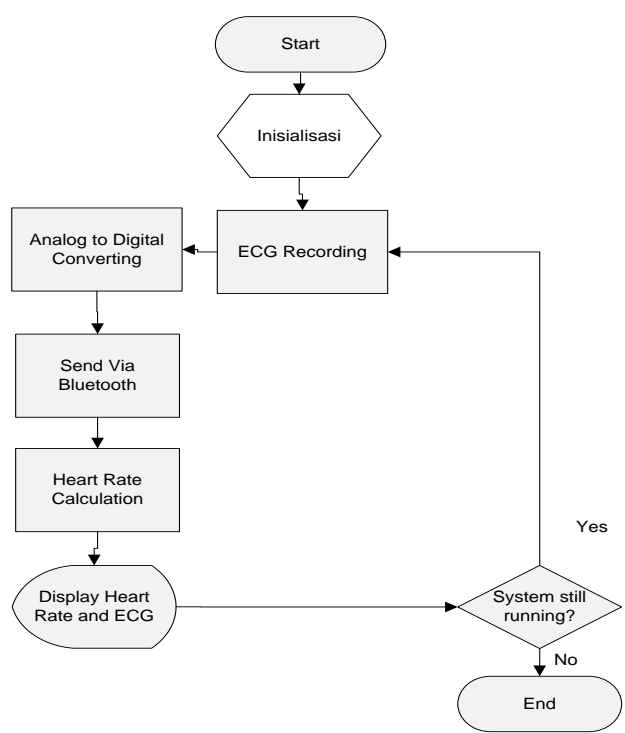

Figure 10. Program Flowchart 


\section{IV.}

\section{RESULT}

The design and realization of the hardware has been completed. After performance testing of the system, the results obtained are described in the following section.

\subsection{System ECG (Hardware)}

This test aims at determining the performance of the device or application when the device is running, including the analog signal amplification results from amplifiers circuit as well as testing for data transmission ECG signal. In the analog section, amplitude of ECG signal also mixed with noise generated at $1.4 \mathrm{~V}$. The noise generated by the device at $160 \mathrm{mV}$, so the Signal to Noise ratio obtained with the formula SNR $=20 . \log$ (A_signal / A_noise) of 18.5 dB. Analog and digital ECG signal is shown in Fig. 11 and Fig. 12.

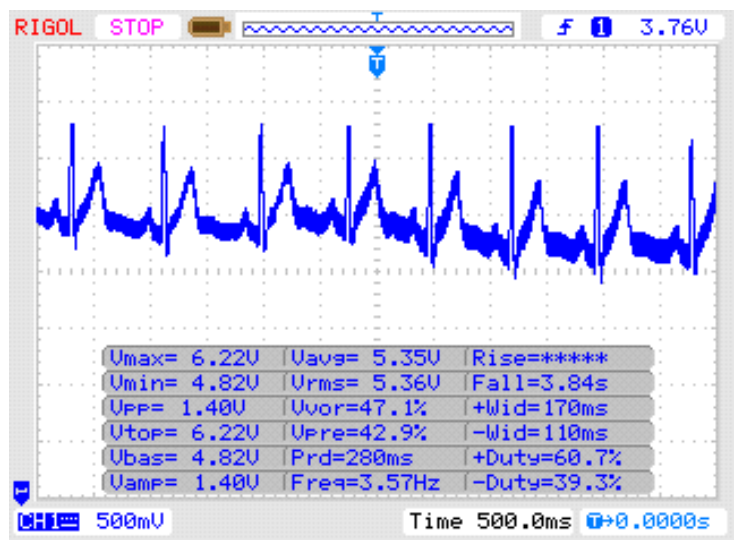

Figure 11. Analog ECG Signal

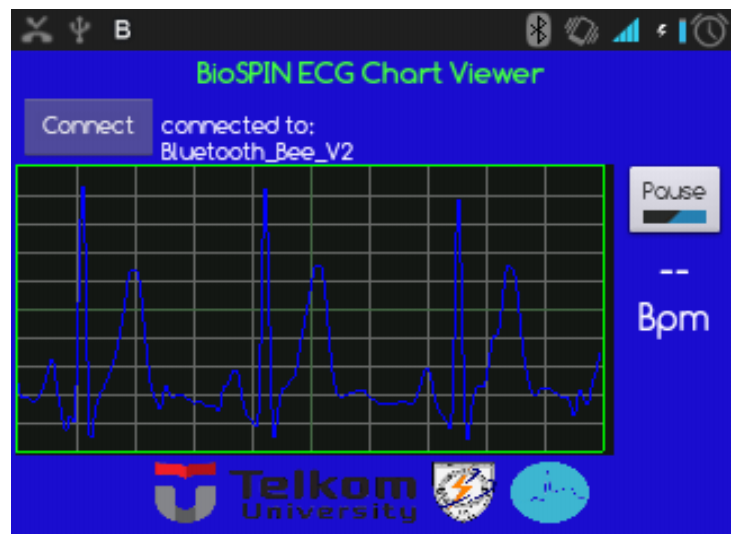

Figure 12. ECG Graph in Smart Phones

\subsection{Battery Life Testing}

These hardware, use two $7.4 \mathrm{~V} 900 \mathrm{mAh}$ batteries. The device can work up to 3 hours. The results of battery test shown in Table 1.

Table 1. Power Consumption Testing

\begin{tabular}{|c|c|c|c|c|}
\hline Buffer & $\begin{array}{c}\text { Baud } \\
\text { Rate }\end{array}$ & $\begin{array}{c}\text { Max. } \\
\text { Time }\end{array}$ & $\begin{array}{c}\text { Graph } \\
\text { Update (s) }\end{array}$ & $\begin{array}{c}\text { Delay } \\
\text { update }\end{array}$ \\
\hline 1 & 9600 & - & - & - \\
\hline 5 & 9600 & $\begin{array}{c}\text { 1Hour } \\
48 \text { minute }\end{array}$ & - & - \\
\hline \multirow{2}{*}{10} & 9600 & $\begin{array}{c}\text { 3Hour } \\
56 \text { minute }\end{array}$ & 0.12 & 0.02 \\
\cline { 2 - 5 } & 38400 & $\begin{array}{c}\text { 2Hour } \\
\text { 28minute }\end{array}$ & 0.106 & 0.006 \\
\hline \multirow{2}{*}{50} & 9600 & $\begin{array}{c}5 \text { Hour } \\
\text { 10minute }\end{array}$ & 0.60 & 0.1 \\
\cline { 2 - 5 } & 38400 & $\begin{array}{c}\text { 3Hour } \\
\text { 48minute }\end{array}$ & 0.515 & 0.015 \\
\hline \multirow{2}{*}{100} & 9600 & $\begin{array}{c}\text { 6Hour } \\
\text { 49minute }\end{array}$ & 1.12 & 0.12 \\
\cline { 2 - 5 } & 38400 & $\begin{array}{c}\text { 4Hour } \\
\text { 38minute }\end{array}$ & 1.03 & 0.03 \\
\hline
\end{tabular}

By transmitting sample of data with small amount of each transmission, it resulted in the application that could not run normally and applications closed. By utilizing large enough of sample size for each transmission, the battery can last longer.

\subsection{Distance of Transmission}

Testing is done by sending 1,000 bytes of data every 10 milisecond with line of sight (LOS) condition (no obstacle). The results of testing are shown in Table 2. 
Table 2. Distance Testing

\begin{tabular}{|c|c|c|c|c|}
\hline No & Distance (m) & $\begin{array}{c}\text { Sample } \\
\text { received }\end{array}$ & $\begin{array}{c}\text { \% sample } \\
\text { missing }\end{array}$ & $\begin{array}{c}\text { Transmit } \\
\text { Delay (s) }\end{array}$ \\
\hline 1 & 1 & 1000 & $0 \%$ & 0.0126 \\
\hline 2 & 2 & 1000 & $0 \%$ & 0.0184 \\
\hline 3 & 5 & 1000 & $0 \%$ & 0.0221 \\
\hline 4 & 10 & 997 & $0.3 \%$ & 0.0293 \\
\hline 5 & 20 & 956 & $4.4 \%$ & 0.0312 \\
\hline 6 & 50 & 879 & $12.1 \%$ & 0.0381 \\
\hline 7 & 100 & 723 & $27.7 \%$ & 0.0523 \\
\hline
\end{tabular}

From the data above, the device can work optimally with distances below $20 \mathrm{~m}$. Furthermore, power consumption used by the ECG is larger when the distance between the transmitter and receiver getting away. This is because of the transmitting device will increase the transmission power to be able to make connection between client-server.

\section{CONCLUSION}

Based on the implementation and testing the system, three conclusion can be drawn from this study. First, the graphics applications are capable of running both I smart-phone display. Second, the devices can work up to 3 hour using two $7.4 \mathrm{~V} 900 \mathrm{mAh}$ batteries. Third, implementation of Bluetooth communication on ECG monitoring device can run optimally at $20 \mathrm{~m}$ with frame of data transmission at 10 sample / frame and baud rate 38,400 bps.

\section{REFERENCES}

[1] S. Widjaya, "EKG Praktis," Binarupa aksara, Jakarta, 1990.

[2] A. Rizal, Jondri, "Wireless LAN Electrocardiogram (ECG)", Proceeding Konferensi Nasional Sistem Informatika 2010, Bali, 2010

[3] AnaesthesiaUK, " The Electro-cardiogram," [online] avalaible at http://www.frca.co.uk/article.aspx?articleid=339 [access date December, 2013]

[4] W. J. Tompkins, "Biomedical Signal Processing," Prentice Hall, New Jersey, 1993

[5] K. Gentry, "BIOE 415: ECG WAV how-to ", [online] avalaible at https://courses.engr.illinois.edu/bioe415/labs/ecgwav.html [access date January, 2014]

[6] ," Datasheet AD620," [online] avalaible at http://www.analog.com/static/importedfiles/data_sheets/AD620.pdf, [access date May, 2012]

[7] ,"Bluetooth Bee,"[online] avalaible at http://www.robotdomestici.it/joomla/component/virtuemart/bluetooth-bee [access date February, 2014] 